\title{
3 Addressing maternal mortality through decriminalizing abortion in Nigeria
}

\author{
Asking the 'woman question'
}

\author{
Ibrahim Obadina
}

\section{Introduction}

Nigeria's abortion laws make it one of the most restrictive countries regarding abortion. ${ }^{1}$ The geometric rise in maternal mortality rate is because of the criminalization of abortion in Nigeria. This approach to abortion in Nigeria calls for immediate action in a variety of ways to ultimately put an end to this horrible and oppressive practice. Most jurisdictions have liberalized abortion laws and are further making reforms aimed at addressing the existing inadequacies in the laws, in manners that redress the oppression of women. The United States Supreme Court's approach and jurisprudence to the self-determination rights relating to abortion is notable. It has contributed a lot in asking the woman question, handing down cases such as Roe v Wade, Doe v. Bolton, Gonzales v Carhart. While acknowledging their contributions, they are not the focus of this paper. Despite advancements in abortion jurisprudence, statutes in Nigeria affecting abortion are yet to recognize a woman's right to decide whether to carry a pregnancy to term as a matter of her autonomy, equality, or selfdetermination. To achieve transformative change and to recognize women as autonomous rights-bearers and effectively tackle the menace of maternal mortality resulting from the restriction on abortion in Nigeria, law makers must confront the regulation and politics of abortion from a feminist perspective. This means reflecting the experiences of women and addressing the gendered implications of abortion restrictions or, simply put, to be effective in addressing the scourge of maternal mortality resulting from unsafe abortion, the statutes must reflect the realities of Nigerian women in their provisions and applications by 'asking the woman question', as this research will show. ${ }^{2}$

The restriction has had a negative impact on women in Nigeria and contributes to the alarming increase in the proportion of maternal death in the country due to unsafe abortion. Although there are various causative factors for maternal mortality in Nigeria, unsafe abortion constitutes the highest percentage of all the factors. This paper critically examines the legal framework for abortion in Nigeria, with a view to making suggestion for reforms to reduce the incidence of maternal mortality by suggesting the expansion of the grounds for abortion and decriminalization in line with international standards.

DOI: $10.4324 / 9781003175049-3$ 
The paper calls for a rethinking of the lifesaving requirement as the sole basis for abortion under the Criminal and Penal Codes operative in the country, by calling for an amendment of the provision or repeal to incorporate experiences and realities of women. It suggests a rights-based approach and the domestication of human rights instruments that Nigeria is signatory to, i.e. the Protocol to the African Charter on Human and Peoples' Rights and on the Rights of Women in Africa, which entered into force in 2005 (the 'Maputo Protocol'). It examines whether the provisions of the Maputo Protocol ask the woman question. It considers what lessons the African Commission, the monitoring body for the African Charter and its Protocols can learn from interpretations and jurisprudence of similar provisions on reproductive rights from other regional and international human rights bodies, such as CEDAW and the European Union on how to interpret provisions dealing with women's rights.

\section{Abortion and maternal death in Nigeria}

Any discussion of abortion in Nigeria logically begins with the conception of a person under Nigerian law. Section 307 of the Criminal Code provides that a child becomes a person capable of being killed when it has completely proceeded in a living state from the body of its mother, whether it has breathed or not, and whether it has an independent circulation or not, and whether the navel string is severed or not. Thus, any other termination of the life in a pregnancy short of this is an abortion. The only permissible ground for performing abortion is to save the life of the mother. Consequently, many women resort to unsafe abortion methods. This leads to abortion-related complications and increasing mortality rate in the country. Unsafe abortions remain a major reproductive health concern in Nigeria since most abortions are carried out illegally and are, as a result, performed by unskilled and semi-skilled physicians. ${ }^{3}$

Criminalizing abortion drives women from hospitals where they could get better medical attention, and make them resort to the use of quacks and crude means in a bid to terminate an unwanted pregnancy. Abortions are a major contributor to maternal mortality, accounting for as many as 30-40\% of maternal deaths in Nigeria and one in eight maternal deaths in the West African sub-region. ${ }^{4}$ The estimated abortion rate was 33 abortions per 1,000 women aged 15 to 49 in 2012. ${ }^{5}$ Abortions account for up to $40 \%$ of maternal deaths in Nigeria, making it the second leading cause of maternal mortality in the country. ${ }^{6}$

According to a research, an estimated 456,000 unsafe abortions are done in Nigeria every year. ${ }^{7}$ A similar study estimates the number of women who engage in unsafe abortions to be at about 20,000 each year. ${ }^{8}$ Research has revealed that only $40 \%$ of abortions are performed by physicians in regular health facilities, while the remaining percentage are performed by non-physicians. ${ }^{9}$ Unwanted pregnancy can and does occur among women from every social, demographic and economic background in Nigeria. Economic, sociocultural and religious factors continue the inequality and lack of respect for the 
rights of women are also responsible for the high rate of abortions in Nigeria. ${ }^{10}$ Thus, whether an abortion is carried out through qualified medical practitioners or quacks, has implications for the rate of abortions. In the face of high pregnancy rates due to lack of contraceptives, poverty, cultural reasons and family planning, the legal restrictions have no doubt failed to take into consideration the different situations of women.

One of most compelling arguments against restrictive abortion laws is that they are the reason why millions of women have recourse to unsafe abortion and as a consequence lose their lives. Hence, the link between unsafe abortion and restrictive laws is well established. ${ }^{11}$ Indeed, it forms the main premise upon which international treaty bodies have recommended the liberalization and decriminalization of abortion laws to reflect the experiences of women. Abortion-related mortality and morbidity are highest in those countries where the law is most restrictive of abortion. It is against this backdrop, that the Maputo Protocol for example, envisages liberalization of restrictive abortion laws across the continent in a manner that guarantees the realization of substantive right to reproductive health of women in Africa. It provides governments with a human rights edifice for taking a lead in reforming laws that impede access to safe abortion.

\section{What is the woman question?}

Feminist researchers adopt different methods of analysis to address different legal questions to bring the values and experience of women to bare on social and legal problems. ${ }^{12}$ Popular perspectives in this regard include rational empiricism, standpoint epistemology, postmodernism and positionality. ${ }^{13}$ Bartlett's article titled 'Feminist Legal Methods', ${ }^{14}$ discusses such topics as feminist practical reasoning, feminist consciousness raising and asking the woman question. ${ }^{15}$ Hence, the approach of this research is to ask the woman question, and determine the implications of asking the question for the provision of abortion law in Nigeria. ${ }^{16}$ Drawing on the provsions of the Maputo Protocol, on liberalization of abortion in Africa, this chapter discusses lessons that can be learned from the approach of the Protocol in advancement of the reproductive health and rights of women. .

The research draws experience from feminist as well as legal and judicial jurisprudence from other jurisdictions, where the woman question has been asked. This approach is designed to identify the gender implications of rules and practices which might otherwise appear to be neutral or objective. ${ }^{17}$ The method is designed to expose how the substance of law may silently and without justification submerge the perspectives of women, and further entrench the patriarchal tradition. ${ }^{18}$ Examining the extant codes through the lenses of the Protocol's interpretive guide and jurisprudence of the African Commission, will, it is argued, promote the legitimacy of liberalizing abortion laws and provide an impetus for the reform of Nigerian abortion law and practice with a focus on the need to advance women's health. 
Asking the woman question means 'examining how the law fails to reflect the experiences and values that seem more typical of women than of men'. ${ }^{19}$ It is on this sense that women in the regulation of society are discriminated against and oppressed and are disadvantaged and require bespoke approaches to issues concerning them. In cases like abortion, it presumes that the law on abortion has ignored and omitted to reflect the realities and experiences and values of women and has put on masculine lenses to look at issues affecting women $^{20}$ to redress existing inequality. ${ }^{21}$

\section{Abortion rights and feminist standards}

Unsafe abortion has been linked to criminalization of abortion in most countries in Africa, and remains a major public health and human rights challenge especially for women in the African region..$^{22}$ It has been argued that the reform of abortion laws in African can go a long way in transforming reproductive rights of women, and has the consequential positive effect of developing the jurisprudence around such rights within domestic legal regimes. ${ }^{23}$

Criminalizing abortion has a social impact which can be damaging to the health of women in the society, though this is contested. ${ }^{24}$ It is a much-controversial area of study, especially as the state has power to determine what is criminal, impose different punishments; exceptions include the circumstances surrounding individual case. ${ }^{25}$ Thus, it is highly affected by a number of factors such as political will, economic status, cultural factors and most importantly for this purpose, the plural nature of the legal system in the country. ${ }^{26}$ Scholars have expressed the opinion that the nature of non-enforcement and implementation of international laws have a lot to contribute to the poor state of reproductive health of women. ${ }^{27}$ Others have also expressed that beyond the existence of international human rights framework, there is also the inherent and internal limits that laws have to secure effective transformation of women's rights in such a multi-cultural, multi-ethnic and religious society. ${ }^{28}$ While the criminalization of abortion is not an end in itself, it serves as a means to hold states accountable for the implementation of laws affecting women especially international and regional human rights provisions. This to scholars, will transform the abortion laws in these jurisdictions from a crime-punishment model to a reproductive health model. ${ }^{29}$

Four ethical principles have provided the foundation for reproductive and sexual rights for women: bodily integrity, personhood, equality and diversity. They form the basis of what provisions on abortion should reflect for it to reflect women's experiences. By incorporating these in the liberalization process, it will not only recognize the associated human rights in accordance with international human rights instruments, it would have the effect of incorporating the immediate experiences of women. For example, bodily integrity has been construed as an individual and a social right with the implication of entitlement to health, procreation and sexuality. As a ground for abortion, threat to the health of a pregnant woman can be particularly enabling when health is 
understood in a holistic sense as envisaged by the WHO, permitting medical abortion when the pregnancy poses threat to health and life of a mother.

More so, treatment of women, as not merely objects and as a means of achieving social goals such as population control, must be assured through decision making autonomy. ${ }^{30}$ The sexual autonomy of women and girls must be given adequate attention. The most prominent basis for the support and criticism of abortion rights is the need to guarantee and protect the right to life, which is the basis of the existence of rights. ${ }^{31}$ Some arguments for permitting a right to abortion depend on denying rights to the foetus. Only persons have rights, and foetuses it is argued, are not yet persons. ${ }^{32}$ Thomson argue that even if the foetus is a person with a right to life, there are limits to what the state can compel women who carry foetuses in their bodies to do. ${ }^{33}$ To ask the woman question in this regard, one may argue that abortion provisions must recognize and give priority to the autonomy of a woman to determine whether she carries a pregnancy or not. This argument is even more compelling especially where the pregnancy poses a threat to her psychological and physical health, life, or because of illicit sexual acts not within her control such as assault or rape. Although some feminists endorse the right to abortion, the issue of abortion cannot easily be reduced to the interests of men versus women. ${ }^{34}$ To some, the perspective of thinking of the foetus and the mother as distinct persons emphasizes their intertwined relationship and therefore unfounded. ${ }^{35}$ The perspective of abortion as a right, having to do with ownership and control of one's body would open the floodgates for abortion on other seemingly impermissible circumstances or trivial grounds. ${ }^{36}$

To view abortion only in terms of individual choice or even as a clash of rights, neglects a range of other relevant considerations including the fact that women and only women get pregnant and bear children; women earn less than men; they are subjected to sexual violence, and they have less familial or political decision-making power than men. This is what led Cook and Howard to argue that the law should focus on accommodating the differences in biology and experience rather than reinforcing the patriarchal stereotype of the role of women, ${ }^{37}$ and that such a law must be sensitive and all-embracing and transformative to value different sexes and their significance. ${ }^{38}$ These concepts and rights are the ideals of a liberalized and gender-sensitive and equalitybased abortion provision; they are recognized as shaping modern laws affecting reproductive rights of women. Thus, for an abortion law to incorporate these standards is to reflect the sensitivity, reality and experiences of women, and would be seen to have asked the ultimate woman question.

The Human Rights Committee in interpreting Art 3 ICCPR submitts that granting abortion rights for rape victims raises questions on the compliance and implementation of Articles 7 and 24 of the ICCPR. i.e. the right not to be subjected to cruel, inhuman and degrading treatment, and the right of minors to special treatment. Similarly, the CEDAW Committee has interpreted Article 12 of CEDAW on the right to health with discrimination on the basis of gender and biology. In addition, sections 33, 42 and 35 of the Constitution of Nigeria 
guarantee the rights to life, non-discrimination and dignity of human persons, and that these rights are inviolable. In a similar vein, the CEDAW Committee in its concluding observation for instance urges Chile to amend abortion laws to permit abortion on the grounds of health, including mental health in compliance with its international human rights obligations. The Committee also urges Zimbabwe to liberalize and decriminalize abortion considering its contribution to maternal mortality, as they violate the right to life of a majority of the victims. Similarly, the treaty monitoring body that supervises government compliance with the ICCPR has also interpreted existing global human rights standards to guarantee a women's right to safe and legal abortion, under certain circumstances as implicating guaranteed rights to equality, non-discrimination, life, liberty, security of the person and the highest attainable standard of health. The CEDAW Committee has also framed the issue of maternal mortality due to unsafe abortion as a violation of women's right to life.

Moreover, Article 2 of the African Charter which is domesticated in Nigeria provides that everyone is equal before the law and that no one should be discriminated against on grounds such as gender, religion, political beliefs or other status. Article 3 similarly guarantees to every individual the right to equality and equal protection of the law. Specifically relating to women, Articles 1 and 2 of the African Women's Protocol prohibit discriminatory practices against women. The African Commission in ruling on the provisions of Articles 2 and 3 in Legal Resource Foundation $v$ Zambia relating to non-discrimination and equality rights emphasizes the importance of fair treatment and just treatment within every legal system for all citizens, and the effect of such treatment on the enjoyment of other rights.

Do the abortion provisions in Nigeria ask the woman question? Admittedly, most countries have had to rely on international human rights law to grant these rights without direct local legislation, In Africa, the African Charter and the Maputo Protocol represent the guiding principle for a liberalized abortion regime. More importantly, the interpretative guide provided by the African Commission in General Comment 2 on the provision on abortion and other rights, offers useful guidance to addressing these concerns, although there is yet to be a direct submission for interpretation on the provisions of Article 14 (2) (c). There are lessons to be drawn from other regional or human rights bodies. For instance, the Commission may draw lessons from CEDAW Committee in the Alyne da Silva Pimentel v. Brazil or other related cases, on how to ask the woman question when addressing a communication affecting the sexual and reproductive health and rights of women. ${ }^{39}$

\section{Nigerian criminal codes and the woman question}

The colonial antecedent of Nigeria created the foundation for the criminalization of abortion. The Offences Against the Person Act, 1861, section 58 remains the foundation of the abortion prohibition in many former British colony jurisdictions like Nigeria. Abortion under the section is prohibited, except when it 
is necessary to save the life of the mother as in the case of the southern part of the country. Although most colonial jurisdictions have reformed their abortion laws, abortion-related offences in Nigeria remain of three kinds. They include attempts to procure abortion, killing of an unborn child, and child destruction. The Criminal Code and the Penal Code make it an offence to cause miscarriage and induce self-miscarriage, pursuant to the provisions of section 228 and 229, as a felony with 14 years' imprisonment.

Similar provisions exist in the code applicable in the northern region under sections 232, 233 and 234 of the Penal Code. Section 232 criminalizes causing miscarriage in the absence of good faith, with up to 14 years' imprisonment, or a fine. The offence of killing an unborn child in Nigeria is created under section 328 and 236 of the Criminal and Penal Codes respectively. The Codes provide for the punishment of life imprisonment for any persons who by an act of omission or commission, prevents a child from being born alive by a woman about to be delivered of a child. Allowance is made under sections 297 and 235 of the Codes, respectively, for a situation where the unborn child may be aborted for the preservation of the life of the mother. This is the only statutory expression of the preservation of the life of a mother as a lawful justification for 'abortion' under Nigerian Law.

To attract the application of the codes, the miscarriage should have been caused voluntarily, and should not have been caused in the process of saving the life of the mother. Any other ground attracts a penal sanction. The English abortion precedent-setting case, $R v$. Bourne, construes section 58, the foundation for the sections of the Nigerian Codes under review in giving interpretation to the meaning of the phrase 'for the purpose of saving the life of the mother'. the court opines:

...The law does not require the doctor to wait until the unfortunate woman is in peril of immediate death... if the doctor is of opinion, on reasonable grounds and with adequate knowledge, that the probable consequence of the continuance of the pregnancy will be to make the woman a physical or mental wreck, the jury are quite entitled to take the view that the doctor who, under those circumstances and in that honest belief, operates, is operating for the purpose of preserving the life of the mother.

The case expands the lifesaving requirement to include situations where the physical and mental health of the mother is threatened. This is in recognition of the right to dignity and health recognized under English human rights. This has been argued to be the important approach required in dealing with abortion cases in common law and several other jurisdictions post Bourne, and premised on this judicial intervention majority of former colonial powers have repealed formerly restrictive positions and liberalized their abortion laws, largely to combat unsafe abortion-related mortality and morbidity. ${ }^{40}$ Although the Nigerian Codes provide for exceptions recognized in emergency cases, 
they are only applicable in saving the life of the mother as a matter of necessity and ineffective in practice.

The failure of the codes to specify the measures required to preserve the mother's life or what it means to save the woman's life is fundamental and profound for the rights and experiences of women. The Nigerian courts have also failed to thread the path of Bourne by recognizing grounds which have the focus of the guaranteed rights of women as evident in the case of $R v$. Edgal, involving a woman seeking abortion on health grounds. The West African Court of Appeal refuses abortion on health grounds and reiterates the lifesaving exception as sole grounds. This case represents, to date, the substantive judicial precedent in Nigeria on abortion. This omission or inability to prescribe such tangible criteria leaves so much at the discretion of the physician, and ignores the rights and liberty of a woman to determine whether to abort even when her health and mental being are at risk. ${ }^{41}$ It gives wide discretion to a physician to address a pregnant woman's circumstances based on his or her personal interpretation of the situation, or where she has been sexually assaulted, raped, or would suffer psychological harm as a result of a pregnancy. The language of the provisions seems to suggest that it is a question of fact to be determined by the physician, and a subjective interpretation without taking the realities and everyday experiences of women into consideration. It is argued that the Codes in this light failed to ask the woman question, thereby contributing to the incidence of clandestine abortions. It is for this reason that most global public health and human rights experts advocate promoting women's reproductive health. ${ }^{42}$ Preventing unsafe abortion related mortality and morbidity includes canvasing for the broadening of the grounds for abortion and decriminalization, with the aim of creating an enabling legal environment recognizing the rights and experiences of women. ${ }^{43}$

To guarantee women's reproductive rights in the context of abortion requires more than merely repealing laws that criminalize abortion. ${ }^{44}$ This would entail aspiring towards a comprehensive reproductive health framework. ${ }^{45}$ The state should not merely decriminalize abortion but must also recognize reproductive health rights, services and implementation mechanisms in order to cater for the needs of women. ${ }^{46}$ Rather than reducing the incidence of unsafe abortions, the restriction has compelled women and girls to resort to clandestine abortion, thereby risking their health and lives. ${ }^{47}$ One out of every seven Nigerian woman or girls aged between 15 and 49, have at some point in time attempted to obtain abortion through unsafe means or through unlicensed means, especially through 'unqualified practitioners or qualified ones working under substandard medical conditions'. ${ }^{48}$ The implication of the restrictive abortion provisions dictates that most services are unregulated and mostly 'very frequently unsafe'. ${ }^{49}$

\section{The Protocol and the woman question}

In the last two decades, most countries have witnessed a gradual change towards liberal abortion laws. Admittedly, most countries have had to rely on 
international human rights law to grant these rights without direct local legislation. A similar approach of liberalization of substantive abortion law that is not accompanied by concrete implementation also exists at the African regional level. In 2003, liberalization in the region received a significant boost through the African Charter on Human and Peoples' Rights (African Charter), when the African Union adopted the Protocol to the African Charter on Human and Peoples' Rights on the Rights of Women in Africa. Article 14(2) of the Protocol has significantly augmented the trend towards liberalization by recognizing abortion as a human right in given circumstances. However, states like Nigeria are failing to implement a legal and administrative framework aimed at liberalizing effectively abortion laws domestically, in a manner that takes the lived experiences of women into consideration. The African Commission in its General Comment 2 on the provision on abortion and other rights in the Protocol, offers useful guidance to addressing these concerns. Drawing lessons from emerging jurisprudence from the CEDAW Committee, the European Court of Human Rights and United Nations treaty bodies are an important step that can be used to mirror the commissions interpretation and render African governments accountable for failure to implement domestic abortion laws. This inter-jurisprudential approach will enable courts, policy makers and legislatures in African countries to pinpoint needed interventions by way of law reforms to abortion in Africa.

Specifically, the CEDAW Committee and Committee on the Rights of the Child have expressed concerns on the state of abortion in Nigeria and the need to repeal, reform, and modify its restrictive laws. Despite these recommendations and advisory opinions, abortion is still criminalized in the country.

The significance and potential of the Protocol lies in its affirmation of reproductive choice and autonomy as a key human right, and contains an unprecedented and explicit woman's right to abortion when pregnancy results from sexual assault, rape or incest; when continuation of the pregnancy endangers the life or health of the pregnant woman and in cases of grave foetal defects that are incompatible with life. These grounds are the focus of the failure of the criminal codes in Nigeria, and which may now be realized by women through enforcing their human rights under the Protocol alongside the domesticated African Charter. In the light of the high rate of maternal death due to unsafe abortion, the adoption of the Protocol seeks to improve these indicators by putting pressure on governments, including addressing the underlying socio-political and healthcare issues that contribute to the depressing state of women's health across the continent..$^{50}$

Article 14(2)(c) of the Protocol provides that:

states parties shall take all appropriate measures to: protect the reproductive rights of women by authorizing medical abortion in cases of sexual assault, rape, incest, and where continued pregnancy endangers the mental and physical health of the mother or the life of the mother. 
The Protocol broadens the grounds for abortion in Africa towards liberalization of abortion laws. It recognizes the reproductive rights of women in line with the experience of women and the consequence of the restrictive laws. ${ }^{51}$ While it is not in doubt that decriminalization is a veritable tool in the woman question quest, this is only a part of the story. A combination of repeal of restrictive abortion laws as well as a comprehensive framework is more effective in addressing maternal mortality. A framework where reproductive rights are recognized considering the experiences of women, production of timely healthcare services and adequate mechanisms for the implementation of the various laws including establishing effective monitoring and remedial process, must be put in place. To complement the Protocol, there is a comprehensive framework for the recognition and enforcement of reproductive rights of women. Obstacles in the way of access to healthcare for women such as the criminalization of abortion have been held to violate the provisions of CEDAW, and the Committee has urged state parties to remove the obstacles and amend such laws. According to Ngwena, unless decriminalization of abortion goes in tandem with state provision of substantive access to abortion services based on need rather than means, the plight of women who need abortion, but have little or no income, is unlikely to change. ${ }^{52}$

It is imperative to examine how the Protocol addresses the woman question differently from the approach by national legislations and in the absence of a direct health right precedent. The African Commission in Doebbler $v$ Sudan and Egyptian Rights Initiative v Egypt, offers guidance relating to women's rights, but not abortion. These cases have affected the development of the jurisprudence and interpretation of the Protocol provisions for guidance by states. The African Commission issues GC No. 2 on Article 14.1 (a), (b), (c) and (f) and Article 14. 2 (a) and (c) of the Protocol, recognizing the persistent rate of abortion on the continent and the fact that many countries are yet to undertake the necessary legislative reforms towards domesticating the relevant provisions of the Protocol with the objective of reversing the maternal mortality trend. The GC 2 provides interpretive guidance on the overall and specific obligations of States Parties towards promoting the effective domestication and implementation of Article 14 of the Protocol.

The GC is also to guide in drafting and presenting State periodic reports, on the legislative and other measures taken to promote and protect the sexual and reproductive health of women and girls. It thus imposes an obligation on states for effective evaluation of steps taken to guarantee reproductive rights. In an important decision in the Alyne case, the CEDAW Committee affirms the violation of Art 2 and 12 of CEDAW when it holds that a state party is directly responsible for the actions of private institutions when it outsources its medical services and that it fails to regulate and monitor such institutions. It also affirms that failure to provide affordable access for all women to adequate abortion care, and effective judicial remedies in line with international standards to address the high rate of maternal mortality, amounts to a violation of the socio-economic and cultural rights. The Committee examines factors such as 
poverty and race and intersectional discrimination in arriving at its decision. ${ }^{53}$ The ruling offers a sample direction to the interpretation of the provisions of the Protocol by the African Commission in handling communication on abortion considering the rate of maternal mortality and challenges of access to abortion services prevalent in Nigeria.

Similarly, in L.C v Peru involving a 13-year-old rape victim who was denied abortion. It establishes obligations on the state to allow abortion when the physical and mental health of women is at stake, especially where the pregnancy results from sexual assault or rape. It calls for decriminalization of abortion on these grounds and affirm states' obligation to provide adequate facilities and effective mechanisms for accountability in protecting women's reproductive rights. It is argued that the provisions of the GC resonate with the standards and ideals of abortion law; section 46 of the GC mandates government to remove laws against abortion, and provides both a legal and social environment conducive for the exercise of women's sexual and reproductive rights.

This guidance in the jurisprudence of the Protocol is aimed at changing the negative experiences women face in the various countries in the application of the substantive, administrative laws, judicial and quasi-judicial bodies. The Protocol imposes on state parties the obligation to protect women's reproductive rights, particularly by authorizing safe abortion on recognized grounds. In addition, the Maputo Plan of Action urges governments to adopt legal policies and frameworks to reduce cases of unsafe abortion, and to develop and implement national action plans to mitigate the prevalence of unintended pregnancies and unsafe abortions. Section 53 of the GC further expresses the obligation imposed on state parties aimed at a comprehensive and reflective of approaches of the woman question, by imposing obligation to ensure availability, accessibility, acceptability and good quality reproductive health care, including family planning, contraception and safe abortion for women. State parties should ensure services are comprehensive, integrated, rights-based, sensitive to the reality of women in all contexts, and free from any coercion, discrimination and violence. This will undoubtedly elevate the abortion provisions beyond a neutral set of regulations, to a more gender and women focused legislation.

It has been argued that the Protocol has contributed significantly to the regime of abortion in Africa. First, is its giving abortion rights an enumerated status at a regional level, furthering the consensus on combating unsafe abortion as a major public peril, promoting the legitimacy of liberalizing abortion laws, and providing an impetus for reform. ${ }^{54}$ This has the effect of reforming most abortion laws in Africa from the criminal outlook for a more holistic human rights outlook. The Nigerian restrictive criminal-codes have been criticized, as they fail to recognize other grounds aimed at the autonomy for women. However, the Protocol has also been criticized as being restrictive for failure to concretely recognize other grounds aimed at a deeper autonomy for women, such as abortion by request and socio-economic grounds. The Protocol is only a template, and Art. 31 states that states may recognize other grounds beyond 
those recognized by the Protocol. Moreover, it does not apply to states who have already recognized these grounds in their laws, such as South Africa.

In comparison with the Criminal Code, the Penal Code sections are much circumscribed for abortion rights, and gives so much room for discretion to the judges against women, who are the subjects of the provisions. They lack required human rights jurisprudence of the various international instruments, especially the innovative approach that Art. 14(2) (c) of the Maputo protocol offers. Since states have duty to respect, protect and fulfil the equality and dignity of women, legislations limiting rights of women such as in the case of criminalized abortion, are void and a violation of international law. If states interpret the refusal of grounds of abortion due to rape without considering that rape and even assault is a violation of the dignity and security of the woman, such a statute has failed to reflect women's experience.

Unfortunately, there is a lack of regional enforcement mechanisms to ensure compliance and implementation of the Protocol to be supervised by the African Commission. The Protocol may also encounter difficulty in achieving its purpose if left for countries to simply ratify without domestication, or transformation into a domestic law. This has been argued as the major challenge for abortion reform in Nigeria. ${ }^{55}$ The pluralistic nature of the legal system has made it difficult for international human rights to be effective. ${ }^{56}$ In Nigeria, section 12 of the Constitution provides that such a treaty will have to be enacted into a domestic statute either by way of amendment of provisions, repeal, or adoption as an act of parliament. This will give power to women seeking abortion to rely on such provision in the domestic legal regime, for effective enforcement. While Nigeria has domesticated the African Charter, and ratified the Protocol, it is yet to domesticate the Protocol. The implication is that the lofty goals of the Protocol are far from achievable without domestication.

\section{Conclusion}

I have argued in this chapter that the restrictive abortion provisions in Nigeria are the reason for the practice of unsafe abortion and a major contributor to the high rate of maternal mortality. The Criminal and Penal Codes only recognize lifesaving as the sole ground for abortion. While this is a colonial heritage, various countries have moved beyond the lifesaving exception to include grounds that reflect the realities of modern times and experiences of women. The research argues that using feminist reasoning, the Codes on abortion fail to ask the woman question.

Against this backdrop, the Maputo Protocol significantly advances human rights protections in Africa to better reflect and incorporate women's experiences. Its significance lies in its affirmation of women's reproductive rights as human rights, and its articulation of women's rights within an African regional context. The legal and moral pressure it exerts over the governments and policymakers responsible for its implementation is commendable. The Protocol 
presents a tremendous opportunity for women's rights advocates in Africa, and could herald a new age of sexual and reproductive health for women throughout the continent. The restrictive provisions in the Nigerian codes ought to be reformed, as they are unsustainable and not reflective of the rights of women. They are also contrary to international human rights obligations that Nigeria is signatory to. Most importantly, the restriction is responsible for the high rate of unsafe abortion in the country and the consequential maternal mortality. It is suggested that Nigeria domesticate the Protocol and transform same into local legislation. Judicial and quasi-judicial bodies adopt the interpretive guidelines from the Africa Charter, General Comments 2 and jurisprudence developed by other international bodies, especially CEDAW Committee, EU, and other regional bodies, in implementing abortion provisions. They constitute important sources of norms and standards for national courts. This will significantly improve the experiences of women seeking to assert their autonomy and right to equality.

The recommendations offered by this chapter is that an effective way to redress and control the rate of maternal mortality through abortion is to consider the disadvantageous position of women and give women a voice in the provisions, application, and implementation of laws dealing with reproductive rights of women. Several international bodies have consistently found these restrictive provisions clearly result in a high rate of unsafe abortions, which often result in loss of lives. Finally, to ask the woman question, laws seeking to overcome the restrictive abortion legislations must clearly be seen from a health rights and feminist perspective. Institutional mechanisms leading to the implementation and application of the laws, which are presently absent, are being addressed. These safeguards must ensure that women's rights are given priority with clear remedial guidelines to challenge such institutional process, which must also be less costly, timely and safe, in order(fine) not to defeat its purpose.

\section{Notes}

1 I Irehobhude Comparative health law and policy: Critical perspectives on Nigerian and global health law (2015) 5.

2 B Oye-Adeniran et al 'Advocacy for reform of the abortion law in Nigeria' (2004) 12 Reproductive Health Matters 210; see also B Oye-Adeniran et al 'Complications of unsafe abortion: A case study and the need for abortion law reform in Nigeria' (2002) 10 Reproductive Health Matters 201-217.

3 As above.

4 Guttmacher Institute 'Abortion worldwide: A decade of uneven progress' (2009) 25-29: M Berer 'National laws and unsafe abortion: The parameters of change' (2004) 12 Reproductive Health Matters 1.

5 Guttmacher Institute (2015) https://www.guttmacher.org/fact-sheet/abortion-nigeria (accessed on 24 October 2020).

6 O Friday 'Preventing unsafe abortion in Nigeria' (1997) African Journal of Reproductive Health 25-36.

7 Guttmacher (n 5). 
8 R Abiodun 'Unsafe abortions cause 20000 deaths a year in Nigeria' (2002) 325 British Medical Journal 7371, 988.

9 S Henshaw et al 'The incidence of induced abortion in Nigeria' (1998) 24(4) International Family Planning Perspectives 156-164.

10 L Bartlett et al 'Risk factors for legal induced abortion-related mortality in the United States' (2004) 103(4) Obstetrics and Gynecology 4, 729-737.

11 C Ngwena 'Reforming African abortion laws and practice: The place of transparency' in R Cook et al (eds) Abortion law in transnational perspective: Cases and controversies (2014) 166; Guttmacher Institute (n. 5) 29; Berer 'National laws and unsafe abortion: The parameters of change' (2004) 12 Reproductive: Health Matters 1.

12 S Andermah et al 'A concise glossary of feminist theory' (1997); A Saulnier Feminist theories and social work: Approaches and application (1996); also E Keller 'Feminism and science signs' (1982) 7 Journal of Women in Culture and Society 588-602.

13 K Bartlett 'Feminist legal methods' (1989-1990) 103 Harvard: Law Review 829.

14 As above.

15 As above.

16 Bartlett (n. 13) 104.

17 E Durojaye \& O Oluduro 'The African Commission on Human and People's Rights and the woman question' (2016) 24 Feminist Legal Studies 323.

18 As above 323-325.

19 J Christopher United Nations and International Law (1997).

20 Durojaye \& Oluduro, (n 17) 324; R Cooks 'Human rights and reproductive self-determination' (1995) 44 The American University Law Review 4, 975-1016.

21 E Durojaye \& O Oluduro, (n 17) 324.

22 C Ngwena (n 11) 166.

23 As above.

24 R Cook 'Stigmatised meanings of criminal abortion law' in R Cook et al (eds) Abortion law in transnational perspective: Cases and controversies (2014) 347-348.

25 R Cook (n 24) 348.

26 B Odunsi \& O Adewole 'Domestication and reception of international reproductive health law and the limits of law; Perspectives from Nigeria and South Africa' in I Irehobhude (ed) Women's health and the limits of law-domestic and international perspectives (2020) 235.

27 R Cook (n 24) 347-348.

28 I Irehobhude (ed) Women's health and the limits of law-domestic and international perspectives (2020) 235.

29 C Ngwena (n 11) 168.

30 I Irehobhude (n 28) 24.

31 D Satz 'Feminist perspectives on reproduction and the family' (2008) Stanford Encyclopedia of Philosophy.

32 T Michael 'Abortion and infanticide' (1972) 2(1) Philosophy and Public Affairs 37-65.

33 J Thomson 'A defence of abortion' (1971) 1 Philosophy \& Public Affairs 1.

34 Satz (n 31) 35.

35 As above.

36 S Correa \& R Petchesky Population policies reconsidered: Health, empowerment, and rights (1994) 107-123.

37 R Cook \& S Howard 'Accommodating women's differences under the women's antidiscrimination convention' (2007) 56 Emory Law Journal 1039, 1052-1056.

38 As above.

39 R Cook 'Human rights and maternal health: Exploring the effectiveness of the Alyne decision' (2013) Journal of Law, Medicine \& Ethics, Global Health and the Law 104.

40 C Ngwena 'Inscribing abortion as a human right: Significance of the protocol on the rights of women in Africa' (2010) 32 Human Rights Quarterly 4, 783-864.Among Africa's 
former colonizers, Portugal has been the most hesitant in implementing liberal reform. D Vilar 'Abortion: The Portuguese case' (2002) 10 Reproductive Health Matters 1, 156, It was only in 2007 that Portugal passed a law permitting abortion on request in the first ten weeks of pregnancy. Associated Press (AP), Portugal Law Liberalizes Abortion (2007).

41 F Londras \& M Enright 'A rights-based approach to abortion' in F Londras \& M Enright (eds) Repealing the 8th Reforming Irish abortion law (2018) 3.

42 Cook (n 39) 348; Londras \& Enright (n 41) 2.

43 Center for Reproductive Rights 'The world's abortion laws map' (2011) http://reproductiverights.org/en/document/the-worlds-abortion-laws-map-2011 (accessed 20 October 2019).

44 Ngwena (n 40) 783.

45 R Cook and Dickens 'Human rights dynamics of law reform' (2003) 25 Human Rights Quarterly 1, 12-14.

46 C Ngwena 'Access to legal abortion: Developments in Africa from a reproductive and sexual health rights perspective' (2007) Health and Human Rights 315.

47 Alan Guttmacher Institute ‘Abortion in Nigeria' factsheet October (2015) https://www .guttmacher.org/fact-sheet/abortion-nigeria (accessed 20 April 2020).

48 A Bankole et al 'Barriers to safe motherhood' 9 (2009) www.guttmacher.org/pubs/2009 /05/28/MotherhoodNigeria.pdf (accessed 20 April 2020).

49 S Henshaw et al 'Severity and cost of unsafe abortion complication treated in Nigerian hospitals' (2008) International Family Planning Perspective 48, 34.

50 Ngwena (n 40) 783-864.

51 As above.

52 As above.

53 Cook (n 39) 106.

54 Ngwena (n 46) 783-864.

55 Odunsi \& Adewole (n 26) 235.

56 As above.

\section{References}

Abiodun, R 'Unsafe abortions cause 20000 deaths a year in Nigeria' (2002) 325 British Medical Journal 7371, 988.

Bankole, A, Adewole, I, Hussain, R, Awolude, O, Singh, S \& Akinyemi, J 'The incidence of abortion in Nigeria' (2015) 41(1) International Perspectives on Sexual and Reproductive Health 170-181.

Bartlett, K 'Feminist legal methods' (1989-1990) 103 Harvard Law Review 829.

Bartlett, L, Berg, C, Shulman, H, Zane, S, Green, C, Whitehead, S \& Atrash, H 'Risk factors for legal induced abortion-related mortality in the United States' (2004) 103(4) Obstetrics and Gynecology 729-737.

Cook, R 'Human rights and maternal health: Exploring the effectiveness of the Alyne decision' (2013) 41 (1) Journal of Law, Medicine and Ethics 103.

Cook, R 'Human rights and reproductive self-determination' (1995) 44(4) The American University Law Review 975.

Cook, R 'Stigmatised meanings of criminal abortion law' in Cook, R (ed) Abortion law in transnational perspective: Cases and controversies (University of Pennsylvania Press 2014).

Cook, R \& Howard, S ‘Accommodating women's differences under the women's antidiscrimination convention' (2007) 56 Emory Law Journal 1039, 1052-1056

Correa, S \& Petchesky, R Population policies reconsidered: Health, empowerment, and rights (Harvard University Press 1994) 107-123. 
Dixon, R \& Nussbaum, M 'Abortion, dignity and a capabilities approach' in Baines, B (ed) Feminist constitutionalism: Global perspectives (Cambridge 2012).

Durojaye, E \& Oluduro, O 'The African commission on human and people's rights and the woman question' (2016) 24 Feminist Legal Studies 323.

Fox, E 'Feminism and science signs' (1982) 7 Journal of Women in Culture and Society 588.

Harding, S and Norberg, K 'New feminist approaches to social science methodologies' (2005) 30(4) Signs: Journal of Women in Culture and Society 2009.

Henshaw, S, Singh, S, Oye-Adeniran, B, Adewole, I, Iwere, N \& Cuca, Y 'The incidence of induced abortion in Nigeria' (1998) 24(4) International Family Planning Perspectives 156.

Irehobhude, I (eds) Women's health and the limits of law-domestic and international perspectives (Routledge 2020).

Liebenberg, S 'Adjudicating social rights under a transformative constitution' in Langford M (ed) Social rights jurisprudence: Emerging trends in international and comparative law (Cambridge 2008).

Londras, F \& Enright, M A rights-based approach to abortion in Repealing the 8th: Reforming Irish abortion law (Bristol University Press; Policy Press 2018).

Michael, T 'Abortion and infanticide' (1972) 2(1) Philosophy and Public Affairs 37.

Ngwena, C (eds) 'Access to legal abortion: Developments in Africa from a reproductive and sexual health rights perspective' in Cook, R and Ngwena, C (eds) Health and human Rights (Ashagate 2007) 315.

Ngwena, C 'Inscribing abortion as a human right: Significance of the protocol on the rights of women in Africa' (2010) 32(4) Human Rights Quarterly 783.

Ngwena, C 'Protocol to the rights of women in Africa: Implications for access to abortion at the regional level' (2010) International Journal of Gynecology and Obstetrics 110.

Ngwena, C 'Reforming African abortion laws and practice: The place of transparency' in Cook, R, Erdman, J \& Dickens, B (eds) Abortion law in transnational perspective: Cases and controversies (University of Pennsylvania Press 2014).

Ngwena, C \& Durojaye, E 'Strengthening the protection of sexual and reproductive health and rights in the African region through human rights: An introduction' in Ngwena, C \& Durojaye, E (eds) Strengthening the protection of sexual and reproductive health and rights in the African region through human rights (PULP 2014).

Odunsi, B \& Adewole, O 'Domestication and reception of international reproductive health law and the limits of law: Perspectives from Nigeria and South Africa' in Irehobhude, I (ed) Women's health and the limits of law-domestic and international perspectives (Routledge 2020).

Ogbu, R 'Illegal abortion in Nigeria: The cringing reality' (2013) available at https://ynaija .com/illegal-abortion-in-nigeria-the-cringing-reality/ (accessed 20 November 2020).

Okonofua, F 'Preventing unsafe abortion in Nigeria' (1997) African Journal of Reproductive Health 25-36.

Oye-Adeniran, B 'Complications of unsafe abortion: A case study and the need for abortion law reform in Nigeria' (2002) 10 Reproductive Health Matters 201.

Oye-Adeniran, B, Long, C \& Adewole, I 'Advocacy for reform of the abortion law in Nigeria' (2004) 12 Reproductive Health Matters 210.

Satz, D 'Feminist perspectives on reproduction and the family' (2008) Stanford Encyclopedia of Philosophy.

Thomson, J 'A defence of abortion' (Fall 1971) 1 Philosophy \& Public Affairs 1. 